\title{
PROJETO TRILHAS DA LEITURA E O ACESSO DEMOCRÁTICO AOS LIVROS
}

\author{
Mauricio Ferreira Chaves ${ }^{1}$
}

\section{RESUMO}

O projeto Trilhas da Leitura é uma iniciativa sem fins lucrativos que busca tornar o livro um objeto acessível a todos por meio da distribuição gratuita e da coleta de obras em ruas, praças e escolas de Contagem, em Minas Gerais, e de outros municípios da região. As práticas democratizantes de acesso à leitura, realizadas pelos idealizadores do projeto, fomentaram a escrita desse estudo que busca divulgar os benefícios do projeto Trilhas da Leitura para a garantia do acesso ao livro por meio das percepções dos leitores envolvidos. Assim, foram realizadas entrevistas, em diversas edições do projeto, para coletar dados objetivos e subjetivos que permitiram uma descrição dos benefícios dessa iniciativa para os leitores participantes. Os dados foram analisados de modo combinado com enfoques estatísticos e no conteúdo das entrevistas realizadas. Portanto, espera-se que este estudo descritivo sirva de motivador para demais projetos e pesquisas que podem, inclusive, pautarem-se em metodologias ativas para sua execução.

Palavras-chave: Leitura; Trilhas da Leitura; Livros; Metodologias Ativas.

\section{ABSTRACT}

Trilhas da Leitura project is a non-profit initiative that seeks to make the book an object accessible to all through the free distribution and collection of works in streets, squares and schools of Contagem, in Minas Gerais, and other municipalities in the region. The democratizing practices of access to reading, carried out by the creators of the project, fostered the writing of this study that seeks to disseminate the benefits of Trilhas da Leitura project to ensure access to the book through the perceptions of the readers involved. Thus, interviews were conducted in several editions of the project to collect objective and subjective data that allowed a description of the benefits of this initiative for the participating readers. The data were analyzed in a combined way with statistical approaches and in the content of the interviews conducted. Therefore, it is expected that this descriptive study will serve as a motivator for other projects and researchthat can even be based on active methodologies for its execution.

Keywords: Reading; Trilhas da Leitura; Books; Active Methodologies.

\section{RESUMEN}

El proyecto Trilhas da Leitura es una iniciativa sin fines de lucro que busca hacer del libro un objeto accesible para todos a través de la distribución y recolección gratuita de obras en calles, plazas y escuelas de Contagem, en Minas Gerais, y otros municipios de la región. Las prácticas democratizadoras de acceso a la lectura, llevadas a cabo por los creadores del proyecto, impulsaron la redacción de este estudio que busca difundir los beneficios del proyecto Trilhas da Leitura para asegurar el acceso al libro a través de las percepciones de los lectores involucrados. Así, se realizaron entrevistas en varias ediciones del proyecto para recoger datos objetivos y subjetivos que permitieran una descripción de los beneficios de esta iniciativa para los lectores participantes. Los datos fueron analizados de manera combinada con enfoques estadísticos y en el contenido de las entrevistas realizadas. Por lo tanto, se espera que este estudio descriptivo sirva de motivador para otros proyectos e investigaciones que incluso puedan basarse en metodologías activas para su ejecución.

Palabras clave: Lectura; Trilhas da Leitura; Libros; Metodologías Activas.

\footnotetext{
${ }^{1}$ Possui graduação em Ciências Contábeis pela Universidade Federal Fluminense (2008); é pós-graduado em Gestão Pública Municipal pela Universidade Federal Fluminense (2012), em Gestão de Saúde Pública na UFF (2018), e em Administração Pública na UFF (2019).
} 


\section{INTRODUÇÃO}

Em paralelo às teorias relativas à execução de trabalhos educativos que envolvam projetos, existem práticas educativas exitosas que ocorrem es espaços assistemáticos ou sistemáticos de ensino, como é o caso do projeto Trilhas da Leitura que teve sua primeira edição em maio de 2011, no Parque Ecológico do Eldorado em Minas Gerais. Depois disso, esse trabalho se expandiu, ganhando as ruas, praças e escolas de Contagem - MG. Com tamanho sucesso, rompeu os limites da cidade e foi percorrer outros municípios, como Betim, Belo Horizonte, Bom Despacho, São Gonçalo do Pará, Sabará, Nova Lima, Lagoa da Prata, Divinópolis e Serra do Cipó. Ao longo de quase sete anos de existência. O projeto Trilhas da Leitura, já distribuiu aproximadamente 180 mil livros dos mais variados temas: literaturas, didáticos, apostilas, revistas, livros técnicos, dentre outros ${ }^{2}$.

Evidencia-se que o referido projeto dissemina a leitura por onde passa e é dotado de caraterísticas como solidariedade e criticidade. Tal experiência apresenta traços de algumas metodologias ativas e pode ser incorporado de modo ordenado, recorrente e intencional no espaço escolar. Por esse motivo, ressaltase que essa iniciativa de cunho assistencial e educacional pode ser uma questão a ser trabalhada em projetos que envolvam metodologias ativas ou ser uma das etapas de projetos de leitura que se pautem na Aprendizagem Baseada em Projetos que é o de mais moderno em relação as novas metodologias educativas.

O referido mostra-se com um essencial instrumento que possibilita à sociedade, de forma difusa e democrática à aquisição de livro, fomentando assim, surgências e manutenção do hábito da leitura, contribuindo por consequência na formação e desenvolvimento da pessoa ser transformador de ambiente/mundo, concebendo a importância das práticas de leitura para o desenvolvimento social, educacional, intelectual, cultural e humano, dentre outros, da pessoa ao longo da vida.

Assim, divulgar iniciativas como o projeto Trilhas da Leitura que é caracterizado como um projeto de importante aporte para a difusão do livro na educação básica, e que permite a aquisição deste, principalmente, para estudantes

${ }^{2}$ Disponível em: http://www.cmc.mg.gov.br/?p=10391 Acesso em: 18 jun. 2021. 
que têm dificuldades econômicas são de evidente relevância para a sociedade em geral. Portanto, em busca de uma democratização da leitura, esse corpus se justifica, pois, como já afirmava Monteiro Lobato, um país se faz com homens e livros.

\section{LEITURA COMO ASPECTO TEÓRICO}

No Dicionário Aurélio, o vocábulo leitura significa ato, arte ou hábito de ler; aquilo que se lê; operação de percorrer, em meio físico, sequências de marcas codificadas que representam informações registradas, e reconvertê-las à forma anterior (como imagens, sons, dados para processamento). O material Pró-letramento elaborado pelo governo federal também define a leitura como:

A leitura é uma prática social que envolve atitudes, gestos e habilidades que são mobilizados pelo leitor, tanto no ato de leitura propriamente dito, como no que antecede a leitura e no que decorre dela (BRASIL, 2008, p. 40).

Nota-se que a leitura é importante e possibilita o conhecimento e o uso de uma grande diversidade de gêneros textuais, e desenvolve habilidades de interpretação oral e escrita, essenciais para as avaliações nacionais e tudo que envolve no contexto da vida cotidiana.

$\mathrm{Na}$ argumentação de Cafiero (2010, p. 85), a leitura é um processo de muitas facetas diferentes; ações sistematicamente organizadas podem contribuir para que o aluno leia melhor. A leitura é um processo cognitivo, histórico, cultural e social de produção de sentidos. Na leitura, não apenas decodificando, isto é, juntando letras, sílabas, palavras, frases, porque ler é muito mais do que apenas decodificar. Ler é atribuir sentidos.

Assim, a leitura é tão significativa que nos motiva ao aprendizado logo nos primeiros anos de nossas vidas. Sem a leitura, o avanço no conhecimento científico torna-se impossível, pois nos detemos ao discurso dos outros.

\section{LEITURA E ASPECTOS SOCIOECONÔMICOS}

A importância socioeconômica dos projetos socioeducacionais que promovem a difusão, de forma democrática, do livro e de outras interfaces de 


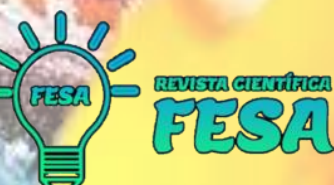

leitura, como e-books, revistas, jornais, dentre outros, que tem em seu cerne o fomento do incentivo às práticas de leitura pelo viés da acessibilidade, principalmente, do livro, relevando que, para muitas pessoas que se encontram, por algum motivo, em situação desfavorável, principalmente pelo fator econômico, têm dificuldades para aquisição de um determinado livro ou outras interfaces de leitura, contribuindo, nesse sentido, para, parte dessas pessoas, não desenvolverem o hábito e habilidades de leitura, reforçando, essenciais competências para o desenvolvimento social, intelectual, cultural, dentre outros humanos, corroborando ainda para a não inclusão social dessas pessoas.

Outra importante vertente pertinente à esta investigação científica é levar à luz da Ciência o crucial aporte de projetos sociais e educacionais que promovem a difusão do livro na sociedade no pertinente que tais projetos fomentam surgências e manutenção no hábito da leitura, bem como, promovem também atividades sociais, educacionais e comunicacionais que permitem intercâmbios e vivências entre leitores, autores de livros e até mesmo editoras, promovendo assim interação e participação de todos envolvidos no processo em si, como ainda renovem as práticas de leitura, essenciais para 0 desenvolvimento social, educacional, intelectual, cultural e, dentre outros, humano da pessoa ao longo da vida, corroborando, assim, nesse sentido, para surgências e desenvolvimento do "ser transformador de mundo", pautando-se na teoria de Freire (2000).

\section{PERCEPÇÕES DOS PARTICIPANTES DO PROJETO TRILHAS DA LEITURA}

O sujeito de pesquisa é o participante pesquisado, individual ou coletivamente, de caráter voluntário que auxilia o pesquisador a alcançar os objetivos da pesquisa. Conforme Ruiz (1996, apud AGUIAR, 2008), o sujeito de uma pesquisa pode ser definido como a pessoa, o fato ou o fenômeno sobre o qual se quer saber algo.

No caso deste artigo, os sujeitos envolvidos na coleta dos dados foram os participantes do projeto Trilhas da Leitura e os membros da comunidade escolar do município de Contagem, em Minas Gerais, que participam das atividades propostas pelo projeto Trilhas da Leitura que buscam promoção de encontros em ambientes em bibliotecas; promoção de encontros em ambientes públicos como 
20 Jun. 2021

F[3

v. 1, n. $5,03-20$

ISSN: $2676-0428$

em praças; promoção de ações em conjunto com autoridades públicas municipais, estaduais e federais a fim de dar sustentabilidade e viabilidade às ações do projeto; promoção de distribuição gratuita de livros e outras interfaces de leitura; promoção de arrecadação de livros e outras interfaces de leitura; promoção de desenvolvimento socioambiental no referente a reciclagem de papéis, relevando que em muitos casos de arrecadam materiais indevidos para o consumo que, no caso dos livros, degradados, sujos e até mesmo com conteúdos defasados e impróprios para as propostas do projeto; promoção de encontros e oficinas com autores de publicações, editoras e sociedades; promoção de rodas de leituras com participações de escritores; promoção de contação de histórias para o público infantojuvenil; promoção, de forma participativa, de livros de autores considerados independentes e sem visibilidade ainda no mercado; e promoção da democratização da leitura por meio de doação de livros as pessoas, cuja situação socioeconômica é considerada desfavorecida.

Acerca da percepção do(a) participante da pesquisa sobre a importância e, portanto, o aporte dos projetos sociais e educacionais que possibilitam alternativas de incentivos às práticas de leitura no referente à essencialidade desses projetos sociais e educacionais no incentivo às práticas de leitura, destacou-se, como principais respostas, obtidas durante aplicação de questionário, ou seja, durante execução de uma das edições do projeto Trilhas da Leitura, como se pode verificar nos Quadros que possui identificadores genéricos para os entrevistados e, ao lado, as respostas obtidas para conteúdo dos inquiridores em destaque.

Ao analisar as respostas obtidas durante a realização das entrevistas aos participantes da pesquisa, observou-se que houve aceitação positiva em relação ao aporte dos projetos sociais e educacionais que possibilitam alternativas de incentivos às práticas de leitura, pois, de acordo com parte dos respondentes da pesquisa, tais projetos sociais e educacionais facilitam à aquisição de livro, revistas e jornais para quem não tem condição para adquiri-los, ou seja, comprálos.

Essa aceitabilidade pode ser um importante dado que pode ser como um contributivo para a inserção de uma versão adaptada e concernente às teorias da Aprendizagem Baseada em Projetos - APB, já que esta destaca que o aluno precisa ser um indivíduo ativo, autônomo e construtor da própria aprendizagem 


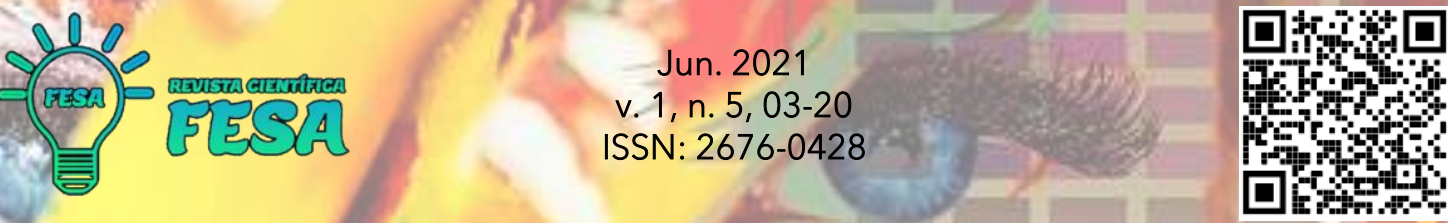

mediada, pois, quando o estudante participa do processo do desenvolvimento de projetos, ele precisa debater sobre a problemática em questão, hipóteses, que objetivos querem alcançar, como alcançar esses objetivos, discutir a relevância das descobertas e, contextualizando na prática para comprovar teorias, pensamentos e, no tocante da culminância desses projetos, 0 conhecimento é compartilhado com um público alvo, logo se conclui que se tem uma aprendizagem ativa e significativa, na qual os conteúdos são retidos de maneira mais efetiva (CONCEIÇÃO, 2021).

Quadro 1. Aporte dos projetos sociais e educacionais no incentivo às práticas de leitura: principais respostas obtidas

\begin{tabular}{|l|l|}
\hline$E_{1}$ & $\begin{array}{l}\text { Facilita à aquisição de livro, revistas e jornais para quem não tem con- } \\
\text { dição para comprá-los. }\end{array}$ \\
\hline $\mathrm{E}_{2}$ & $\begin{array}{l}\text { Além de contribuir com a educação de nossos filhos, é um espaço im- } \\
\text { portante para trocar ideais com outros leitores. }\end{array}$ \\
\hline $\mathrm{E}_{3}$ & $\begin{array}{l}\text { Por meio destes projetos, podemos levar livros os quais se fôssemos } \\
\text { comprar, não teríamos condições financeiras. }\end{array}$ \\
\hline $\mathrm{E}_{4}$ & $\begin{array}{l}\text { Possibilitam a doação de livros para a comunidade carente, ajudando } \\
\text { muitas pessoas sem condições a criar o hábito da leitura, principal- } \\
\text { mente, nas crianças e jovens carentes. }\end{array}$ \\
\hline $\mathrm{E}_{5}$ & $\begin{array}{l}\text { Estes projetos permitem acesso à leitura por meio de doação de livros } \\
\text { feita a comunidade, principalmente, às pessoas carentes. }\end{array}$ \\
\hline $\mathrm{E}_{6}$ & $\begin{array}{l}\text { Como educadora, acredito que estes projetos contribuem para a educa- } \\
\text { ção por meio da doação de livros, incentivando adultos, jovens e crian- } \\
\text { ças a terem mais contato com o livro, essencial para a educação. }\end{array}$ \\
\hline $\mathrm{E}_{7}$ & $\begin{array}{l}\text { Acesso gratuito e oportunidade de adquirir conhecimento por meio das } \\
\text { práticas de leitura com os livros ganhos no projeto. }\end{array}$ \\
\hline $\mathrm{E}_{8}$ & $\begin{array}{l}\text { Estes projetos nos permitem a conhecer autores, muitos independentes } \\
\text { e moradores em nossa comunidade. }\end{array}$ \\
\hline $\mathrm{E}_{9}$ & $\begin{array}{l}\text { Estes projetos contribuem com a mudança de cultura, facilidade de co- } \\
\text { municação e aquisição de conhecimento por meio dos livros recebidos } \\
\text { gratuitamente. }\end{array}$ \\
\hline $\mathrm{E}_{10}$ & $\begin{array}{l}\text { Estes projetos facilitam interação entre as pessoas, pois durante o } \\
\text { evento, pode-se trocar opiniões e experiências de leituras, além de po- } \\
\text { der levar livros com histórias novas e o melhor, gratuitamente, sem } \\
\text { custo para o leitor. }\end{array}$ \\
\hline
\end{tabular}

Fonte: Próprio autor, 2019.

Nesse sentido, segundo ainda parte dos respondentes da pesquisa, além de contribuir com a educação, principalmente das crianças e jovens, as ações sociais e educacionais desenvolvidas por estes projetos possibilitam aos participantes um espaço importante para trocar ideais com outros leitores, pois, 


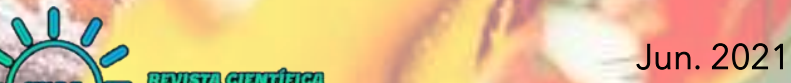

FEged

se pode crer que por meio destes projetos, os participantes das atividades desenvolvidas podem levar livros para a casa, salientando que, se os quais fossem comprados, para muitas pessoas seriam muito improvável pelo fato dessas se encontrarem em desfavoráveis condições financeiras.

Essas informações são relevantes para a aplicabilidade da Aprendizagem Baseada em Projetos - ABP no espaço escolar, pois os estudantes necessitam de acesso ao conhecimento de diferentes formas, pois não há como nivelar o acesso à informação em todo território nacional, visto que o Brasil é dotado de diferentes realidades e vasta desigualdade. Conforme Diniz (2015, p. 13) cita, "A aprendizagem baseada em projetos como método de pesquisa estimula os alunos a adquirir conhecimentos e habilidades, possibilitando a interdisciplinaridade em torno de investigação de questões complexas". Sobre esse adaptar-se às modernidades educativas e tecnológicas, Souza (2021) revela que:

Cada vez mais, constata-se que a tecnologia tem proporcionado novas formas de relação para a humanidade, ao longo do percurso histórico social, na tentativa de solução de problemas e maior agilidade no desenvolvimento de tarefas. Ao mesmo tempo, percebese a importância que esta mesma tecnologia precisa ter no ambiente escolar, entendendo que a escola pode e deve inserir as diferentes mídias para contextualização, aplicação, construção e produção de conhecimento (SOUZA, 2021, p. 75).

Para parte dos participantes, os projetos que fomentam ações sociais e educacionais possibilitam a doação de livros para a comunidade carente, ajudando muitas pessoas sem condições a criar o hábito da leitura, principalmente, nas crianças e jovens carentes, o que leva a crer que tais projetos permitem acesso à leitura por meio de doação de livros feita a comunidade, principalmente, às pessoas carentes e que, ainda, leva a crer que estes projetos contribuem para a educação por meio da doação de livros, incentivando adultos, jovens e crianças a terem mais contato com o livro, essencial para a educação.

Nesse viés, se pode afirmar que projetos como o Trilhas da Leitura garante acesso gratuito e oportunidade de aquisição de conhecimento por meio das práticas de leitura com os livros doados pelo projeto. Ou seja, analisando as respostas obtidas durante a aplicabilidade do questionário durante execução do projeto Trilhas da Leitura, percebeu-se que para parte dos participantes, estes 
Q10 Jun. 2021

$5 \sqrt[3]{30}$

projetos permitem que os envolvidos conheçam autores, muitos independentes e moradores da comunidade, relevando um essencial aporte dos projetos sociais e educacionais, como o Trilhas da Leitura, de fomentar visibilidade à escritores independentes.

Portanto, corroborando, alicerçando nas respostas obtidas dos participantes, que tais projetos contribuem para com a mudança de cultura, facilidade de comunicação e aquisição de conhecimento por meio dos livros recebidos gratuitamente. Assim, parafraseando Santos (2007, p. 479), ser letrado extrapola a leitura do vocabulário científico, é ser capaz de "conversar, discutir, ler e escrever coerentemente em um contexto não-técnico, mas de forma significativa" refletindo o impacto do conhecimento tecnológico e científico na sociedade, onde ser letrado é o propósito da educação básica de formação para a cidadania.

Em suma, analisando as respostas, projetos, como o Trilhas da Leitura, facilitam interação entre as pessoas, pois durante a pesquisa de campo verificouse que muitas pessoas trocavam opiniões e experiências de leituras, além de, poder levar livros com histórias novas e o melhor, gratuitamente, sem custo para o leitor, principalmente, para aquele que se encontra em condição socioeconômica desfavorável por algum motivo, denotando-se que projetos sociais e educacionais como o Trilhas da Leitura tem crucial aporte socioeducacional, principalmente no referente ao incentivo às práticas de leitura, salientando que tais práticas são essenciais para, dentre outros, o desenvolvimento sociocultural, educacional, intelectual e humano ao longo da vida de uma pessoa.

Ao analisar as respostas dos respondentes participantes da pesquisa como se pode observar no próximo quadro leva a crer que, conforme as percepções dos participantes da pesquisa acerca do aporte do projeto, este promove, dentre outras: práticas de leitura por meio da doação de livros de forma itinerante dentro e fora do estado de Minas Gerais; intercâmbios de materiais de leitura (livros, revistas e jornais) entre os envolvidos no projeto; inclusão social por meio da acessibilidade ao livro; e práticas de convívio à leitura por meio de socialização entre leitores e escritores. A seguir, têm-se as respostas na íntegra: 


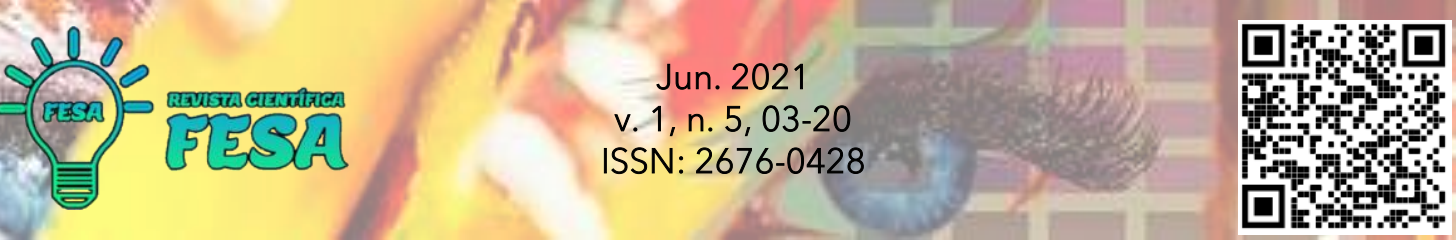

Quadro 2. Principais ações efetivas do projeto Trilhas da Leitura

\begin{tabular}{|l|l|}
\hline $\mathrm{E}_{1}$ & $\begin{array}{l}\text { Doação de livros, revistas e outros materiais de leitura para as comuni- } \\
\text { dades de várias cidades do estado de Minas Gerais. }\end{array}$ \\
\hline $\mathrm{E}_{2}$ & $\begin{array}{l}\text { Doação de materiais danificados e impróprios para as práticas de leitura } \\
\text { para associações de reciclagem de papel. }\end{array}$ \\
\hline $\mathrm{E}_{3}$ & $\begin{array}{l}\text { Promove intercâmbios de materiais de leitura (livros, revistas e jornais) } \\
\text { entre os envolvidos no projeto. }\end{array}$ \\
\hline $\mathrm{E}_{4}$ & $\begin{array}{l}\text { Incentiva a Responsabilidade Socioambiental das empresas que promo- } \\
\text { vem ações de arrecadação de livros e outras interfaces de leitura con- } \\
\text { tribuindo para o fomento da continuidade das atividades sociais e edu- } \\
\text { cacionais desenvolvidas pelo projeto. }\end{array}$ \\
\hline $\mathrm{E}_{5}$ & $\begin{array}{l}\text { Divulgação da importância da participação coletiva no processo de difu- } \\
\text { são do aporte da leitura para o desenvolvimento social, educacional, } \\
\text { econômico, humano e dentre outros. }\end{array}$ \\
\hline $\mathrm{E}_{6}$ & Promove inclusão social por meio da acessibilidade ao livro. \\
\hline $\mathrm{E}_{7}$ & $\begin{array}{l}\text { Promove práticas de convívio à leitura por meio de socialização entre } \\
\text { leitores e escritores. }\end{array}$ \\
\hline $\mathrm{E}_{8}$ & Incentiva a prática de leitura infantil por meio de rodas de leitura. \\
\hline $\mathrm{E}_{9}$ & $\begin{array}{l}\text { Promove cooperação entre entidades públicas e privadas no referente } \\
\text { à promoção de acessibilidade ao livro para as comunidades carentes. }\end{array}$ \\
\hline $\mathrm{E}_{10}$ & $\begin{array}{l}\text { Promove as práticas de leitura por meio da doação de livros de forma } \\
\text { itinerante dentro e fora do estado de Minas Gerais. }\end{array}$ \\
\hline
\end{tabular}

Fonte: Próprio autor, 2019.

Além das promoções citadas, o projeto Trilhas da Leitura, conforme os participantes, fomenta doação de livros, revistas e outros materiais de leitura para as comunidades de várias cidades do estado de Minas Gerais, levando a crer que o Trilhas da Leitura oportuniza acessibilidade difusa e democrática, principalmente do livro, à todas as pessoas, incluindo aquelas que se encontram em situação socioeconômica desfavorável, incentivando, assim, de forma geral, a promoção da inclusão social por meio da acessibilidade ao livro, como também, o incentivo à prática de leitura, principalmente da leitura infantojuvenil, podendo destacar as atividades socioeducativas de leitura denominadas de rodas de leitura, o que leva a crer que o projeto fomenta a inclusão social de forma participativa por meio da divulgação da importância da participação coletiva no processo de difusão do aporte da leitura para o desenvolvimento social, educacional, econômico, humano e dentre outros.

A reflexão e o acesso ao conhecimento são duas variáveis que possuem fomento mútuo e estão presentes como uma das preocupações dos órgãos voltados à pesquisa no Brasil. 
Para desenvolver um país é necessário desenvolver pessoas: elevar o patamar de informação disponível e prover a população de conhecimentos básicos de ciência e tecnologia [...]Além disso, é necessário estimular os jovens a se tornarem profissionais da ciência e da tecnologia, para avançarmos no conhecimento existente. Assim, é preciso que desde os primeiros anos da educação formal os estudantes sejam postos em contato com a cultura científica, ou seja, com a maneira científica de produzir conhecimento e com as principais atividades humanas que têm moldado o meio ambiente e a vida humana ao longo da história (CNPQ, 2018c).

Nesse contexto, ao analisar as respostas apresentadas no quadro anterior, se pode afirmar que o projeto Trilhas da Leitura tem essencial aporte social, educacional e educomunicacional, dentre outros, além de econômico por fomentar, alicerçando nas respostas dos participantes, inclusão social por meio da acessibilidade ao livro, salientando que uma das atividades socioeducacionais e comunicacionais desenvolvidas pelo projeto Trilhas da Leitura se apoia nas práticas de convívio à leitura por meio de socialização entre leitores e escritores, levando a crer que este promove oportunidades de relações comunicacionais entre autores de obras literárias e de outros gêneros com aspirantes à escritores, levando a crer, por consequência, promoção de incentivos novos de produção de obras literárias e de outros gêneros.

Ao analisar as respostas dos participantes respondentes da pesquisa, como se pode observar os motivos que levam a uma pessoa a não ler um livro, a resposta que se destaca é o alto custo financeiro, pois os livros são considerados caros, principalmente para quem recebe salário-mínimo, pois para parte dos respondentes participantes da pesquisa, a renda familiar não é compatível com os preços de livros praticados no comércio nacional brasileiro, o que levam as muitas pessoas a não adquirirem livros por falta de condição financeira, o que leva a crer que, para muitas famílias que vivem em condições desfavoráveis socioeconômicas por algum motivo, o livro se torna um objeto supérfluo diante às outras necessidades socioeconômicas como, podendo destacar, a habitação (relevando que muitas famílias têm despesas com aluguel); e alimentação, além de outras contas essenciais como a da água e iluminação elétrica, consideradas essenciais para o cotidiano da atual sociedade. 


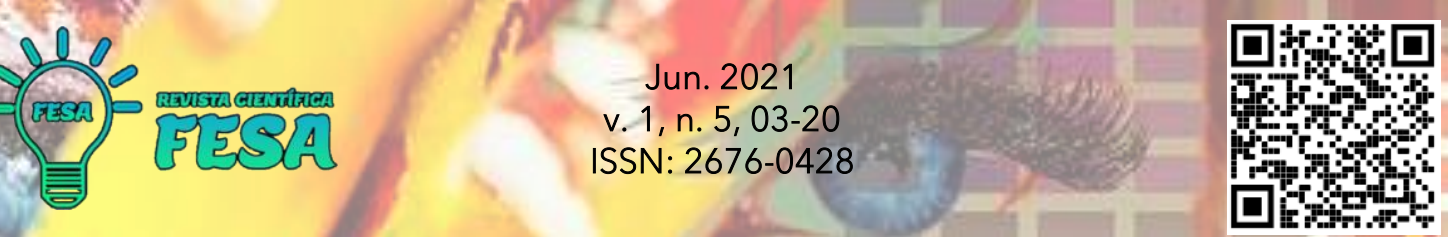

Quadro 3. Motivos que levam a uma pessoa a não ler um livro

\begin{tabular}{|l|l|}
\hline $\mathrm{E}_{1}$ & $\begin{array}{l}\text { Alto custo financeiro, pois os livros são considerados caros, principal- } \\
\text { mente para quem recebe salário-mínimo. }\end{array}$ \\
\hline $\mathrm{E}_{2}$ & $\begin{array}{l}\text { Número considerado insatisfatório de bibliotecas públicas, principal- } \\
\text { mente em comunidades carentes }\end{array}$ \\
\hline $\mathrm{E}_{3}$ & $\begin{array}{l}\text { Não ter renda compatível com os preços de livros praticados no comér- } \\
\text { cio nacional brasileiro, o que levam a muitas pessoas a não adquirirem } \\
\text { livros por falta de renda. }\end{array}$ \\
\hline $\mathrm{E}_{4}$ & Falta de cultura de incentivo de leitura por muitas famílias. \\
\hline $\mathrm{E}_{5}$ & $\begin{array}{l}\text { Muitos pais e/ou responsáveis não terem o hábito de ler para as crian- } \\
\text { ças. }\end{array}$ \\
\hline
\end{tabular}

Fonte: Próprio autor, 2019

Alicerçando nas respostas apresentadas no quadro anterior, se pode acreditar que para parte dos participantes respondentes da pesquisa, em relação à quantidade de bibliotecas públicas dispostas nas comunidades, o número considerado é insatisfatório de bibliotecas públicas, principalmente em comunidades carentes.

Essa autonomia que as bibliotecas possibilitam aos estudantes também é percebida na Aprendizagem Baseada em Projetos - ABP que, como destacam Quiroz e Castillo (2017, p. 118), "para que os alunos possam adquirir os conhecimentos e habilidades essenciais para atuar de forma adequada na esfera social e profissional no século 21 , é necessário passar do ensino centrado no professor para o ensino centrado no aluno". Prescindir desses espaços públicos aumenta a desigualdade e imobiliza o estudante em busca do conhecimento.

Um ponto apresentado, destacado por parte dos participantes respondentes da pesquisa se refere à pouca ou nenhuma acessibilidade na internet de algumas obras, sejam essas parciais ou completas, pois, para muitas pessoas, mesmo não tendo acessibilidade a Rede Mundial de Computadores em casa, seria mais viável que todas as obras, essencialmente fossem dispostas gratuitamente pela Internet, viabilizando assim, oportunidades de forma difusamente democrática de obras, pois à acessibilidade à Internet, conforme respostas obtidas em campo durante a coleta de dados, revelaram ser mais fácil ter acessibilidade ao sinal de Internet (tanto no sentido econômico quanto tecnológico) do que financeiramente no sentido de aquisição do livro, isto conforme parte dos respondentes participantes da pesquisa, salientando que as 
respostas foram obtidas durante as atividades desenvolvidas pelo projeto Trilhas da Leitura.

\begin{abstract}
Com a popularização da internet, no mundo como um todo, a noção de tempo ganhou diferentes conotações, assim como sua administração e seu aproveitamento. O que se evidencia, cada vez mais, são pessoas conectadas por um longo período, negligenciado a execução de ações importantes para a vida social humana (SILVA, 2021, p. 39)
\end{abstract}

Outro ponto revelador apresentado, considerado crucial, no quadro anterior, leva a crer que muitas famílias deixam as práticas de leitura, principalmente, infantojuvenis exclusivamente para a escola, pois parte dos participantes respondentes da pesquisa, afirmaram que há falta de cultura de incentivo de leitura por muitas famílias, além de, muitos pais e/ou responsáveis, segundo respostas obtidas em questionário aplicado durante pesquisa de campo, não terem o hábito de ler, principalmente para as crianças, levando a crer que o ambiente escolar, para muitas crianças e jovens é o único lugar onde se há incentivo às práticas de leitura e consequentemente da escrita, consideradas essenciais para o desenvolvimento social, educacional, intelectual e dentre outras humano, ressaltando, por fim, essenciais para a própria inclusão social da pessoa dentro de sua comunidade/grupo social/sociedade.

Em suma, ao analisar tais respostas, se pode afirmar que (a) há necessidade de se implantar mais bibliotecas públicas, munidas de obras literárias e didáticas atualizadas, e, disponibilizar essas para a comunidade, principalmente, para as consideradas em situações desaforáveis socioeconomicamente, fomentando, nesse viés à acessibilidade às práticas de leitura, principalmente para as crianças e jovens moradores dessas comunidades; (b) há necessidades de se criar programas efetivos e eficazes para o fomento de cultura de incentivo de leitura dentro do seio familiar, promovendo nesse sentido, o fomento da criação do hábito do adulto em ler para uma criança, incentivando a criança a criar o seu próprio interesse e gosto pelas práticas da leitura; (c) se torna essencial criar programas sociais que permitem, principalmente as famílias carentes adquirirem principalmente gêneros literários e didáticos gratuitamente, promovendo assim a plena difusão de forma democrática das práticas de leitura, considerando que para muitas dessas 


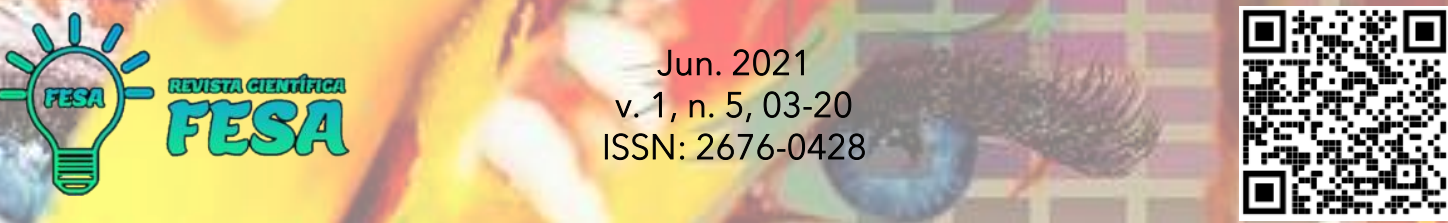

famílias o livro tem um custo financeiro considerado alto, fazendo com que esses livros sejam considerados artigos inacessíveis para essas famílias devido ao seu custo financeiro.

Em relação aos benefícios da leitura, conforme as respostas dos participantes respondentes da pesquisa, destacam-se, como benefícios das práticas de leitura as práticas de leitura agem como portais de novos conhecimentos e saberes, permitindo, de forma subjetiva, que cada leitor vá a um lugar específico, de forma imaginativa; melhoram o convívio social, pois pessoas acostumadas a ler muito, têm mais habilidades em escrever e se comunicar melhor, pois tem facilidades de compreender e se fazer compreenderem no processo comunicacional humano; e, promove mais conhecimento pelo fato da pessoa ter mais acessibilidade as inúmeras informações.

Quadro 4. Benefícios da leitura

\begin{tabular}{|l|l|}
\hline $\mathrm{E}_{1}$ & Desenvolvimento social, educacional, intelectual e humano da pessoa. \\
\hline $\mathrm{E}_{2}$ & Promove o hábito da leitura ao longo da vida da pessoa. \\
\hline $\mathrm{E}_{3}$ & Promove o desenvolvimento do raciocínio lógico. \\
\hline $\mathrm{E}_{4}$ & $\begin{array}{l}\text { Promove o desenvolvimento da linguagem (contribui para o desenvolvi- } \\
\text { mento do ato do falar bem e corretamente). }\end{array}$ \\
\hline $\mathrm{E}_{5}$ & $\begin{array}{l}\text { Promove a inclusão social, pois quem ler bem, escreve bem e se faz ser } \\
\text { entendido melhor em sua sociedade. }\end{array}$ \\
\hline $\mathrm{E}_{6}$ & $\begin{array}{l}\text { Por meio da habilidade e competência de leitura a pessoa tem mais } \\
\text { oportunidades no competitivo mercado de trabalho. }\end{array}$ \\
\hline $\mathrm{E}_{7}$ & $\begin{array}{l}\text { Promove mais conhecimento pelo fato da pessoa ter mais acessibilidade } \\
\text { as inúmeras informações. }\end{array}$ \\
\hline $\mathrm{E}_{8}$ & $\begin{array}{l}\text { Melhora o convívio social, pois pessoas acostumadas a ler muito, têm } \\
\text { mais habilidades em escrever e se comunicar melhor, pois tem facilida- } \\
\text { des de compreender e se fazer compreenderem no processo comunica- } \\
\text { cional humano. }\end{array}$ \\
\hline $\mathrm{E}_{9}$ & $\begin{array}{l}\text { Para famílias que tem o costume de ler, tais ações permitem mais diá- } \\
\text { logos e trocas de ideias entre os membros dessas famílias. }\end{array}$ \\
\hline $\mathrm{E}_{10}$ & $\begin{array}{l}\text { As práticas de leitura agem como portais de novos conhecimentos e sa- } \\
\text { beres, permitindo, de forma subjetiva, que cada leitor vá a um lugar es- } \\
\text { pecífico, de forma imaginativa. }\end{array}$ \\
\hline
\end{tabular}

Fonte: Próprio autor, 2019.

Denota-se, como relevante, ainda analisando o quadro anterior, que, para parte dos respondentes participantes da pesquisa, outro benefício das práticas de leitura se pauta que tais promovem a inclusão social, pois quem ler bem, 
escreve bem e se faz ser entendido melhor em sua sociedade, além de, para muitos dos participantes respondentes da pesquisa, é por meio da habilidade e competência de leitura que a pessoa tem mais oportunidades no competitivo mercado de trabalho, levando a crer que, para a plena aceitação da pessoa no atual mercado de trabalho, se faz essencial que está seja alfabetizada e dotada de habilidades e competência tanto nas práticas de leitura quanto da escrita.

Sobre a importância do ato de ler, González (2015) destaca que "existem práticas de ensino que estimulam uma maior participação dos alunos, conduzindo a um trabalho motivador que estimula o pensamento criativo e inovador, que potencializa sua autonomia e facilita a aprendizagem de competências transversais e profissionais". De modo complementar, entende-se que a Aprendizagem Baseada em Projetos - ABP desempenha um papel importante em alcançar essas expectativas, à medida que os alunos aprendem construindo novas ideias ou conceitos, em um papel ativo em sua própria aprendizagem por meio de projetos que têm aplicações no mundo real (SILVA, 2020).

Ao continuar analisando o quadro anterior, percebe-se que para parte dos participantes respondentes da pesquisa, se configura como essencial benefício das práticas de leitura a melhoria da interrelação comunicacional no âmbito do convívio social, pois, para parte dos respondentes da pesquisa, o hábito da leitura fomenta melhora do convívio social, pois, para parte dos participantes respondentes da pesquisa, pessoas acostumadas a ler muito, têm mais habilidades em escrever e se comunicar melhor, pois tem facilidades de compreender e se fazer compreenderem no processo comunicacional humano, o que leva a crer que um dos benefícios das práticas de leitura é a inclusão social da pessoa em seu grupo/comunidade/sociedade.

Em suma, uma análise ampla do quadro anterior leva a crer que para o desenvolvimento social, educacional, intelectual e dentre outro sociohumano e educomunicacional se faz essencial como principal aporte a criação e manutenção do hábito das práticas de leitura ao longo da vida da pessoa e que nesse sentido, cruzando informações obtidas acerca dos motivos que levam a uma pessoa a não ler um livro se faz essencial promover programas efetivos e eficazes que incentivam a leitura do adulto para uma criança, fazendo como que escola e família se unem para a formação e manutenção do hábito da leitura 


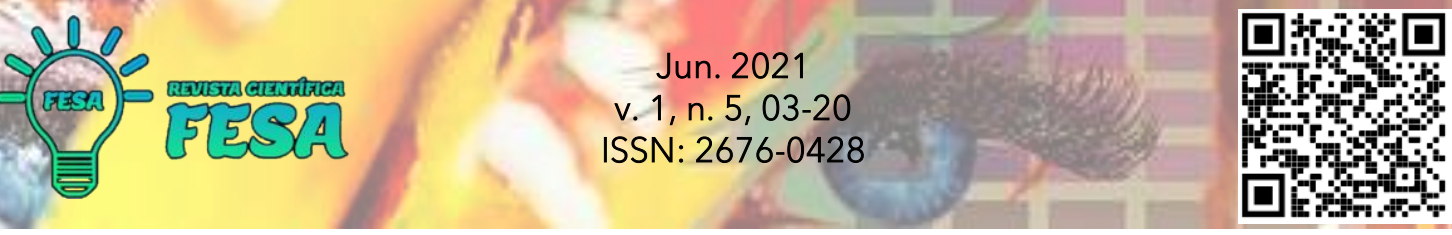

desde a infância; e de programas que permitem a aquisição de livros, principalmente dos gêneros literários e didáticos gratuitamente a fim de, oportunizar a difusão de forma democrática, especialmente para às famílias de baixa renda à aquisição de interfaces de leitura, podendo destacar o livro ou interfaces de leitura digital.

Por fim, decidiu-se listar as principais ações efetivas do projeto a fim de estabelecer um percurso prático para se conhecer por completo tal ação educativa.

Quadro 5. Principais ações efetivas do projeto Trilhas da Leitura

\begin{tabular}{|c|c|}
\hline$E_{1}$ & $\begin{array}{l}\text { Doação de livros, revistas e outros materiais de leitura para as comuni- } \\
\text { dades de várias cidades do estado de Minas Gerais. }\end{array}$ \\
\hline $\mathrm{E}_{2}$ & $\begin{array}{l}\text { Doação de materiais danificados e impróprios para as práticas de leitura } \\
\text { para associações de reciclagem de papel. }\end{array}$ \\
\hline $\mathrm{E}_{3}$ & $\begin{array}{l}\text { Promove intercâmbios de materiais de leitura (livros, revistas e jornais) } \\
\text { entre os envolvidos no projeto. }\end{array}$ \\
\hline $\mathrm{E}_{4}$ & $\begin{array}{l}\text { Incentiva a Responsabilidade Socioambiental das empresas que promo- } \\
\text { vem ações de arrecadação de livros e outras interfaces de leitura con- } \\
\text { tribuindo para o fomento da continuidade das atividades sociais e edu- } \\
\text { cacionais desenvolvidas pelo projeto. }\end{array}$ \\
\hline$E_{5}$ & $\begin{array}{l}\text { Divulgação da importância da participação coletiva no processo de difu- } \\
\text { são do aporte da leitura para o desenvolvimento social, educacional, } \\
\text { econômico, humano e dentre outros. }\end{array}$ \\
\hline $\mathrm{E}_{6}$ & Promove inclusão social por meio da acessibilidade ao livro. \\
\hline$E_{7}$ & $\begin{array}{l}\text { Promove práticas de convívio à leitura por meio de socialização entre } \\
\text { leitores e escritores. }\end{array}$ \\
\hline $\mathrm{E}_{8}$ & Incentiva a prática de leitura infantil por meio de rodas de leitura. \\
\hline $\mathrm{E}_{9}$ & $\begin{array}{l}\text { Promove cooperação entre entidades públicas e privadas no referente } \\
\text { à promoção de acessibilidade ao livro para as comunidades carentes. }\end{array}$ \\
\hline $\mathrm{E}_{10}$ & $\begin{array}{l}\text { Promove as práticas de leitura por meio da doação de livros de forma } \\
\text { itinerante dentro e fora do estado de Minas Gerais. }\end{array}$ \\
\hline
\end{tabular}

Fonte: Próprio autor, 2019.

No relevante ao quadro anterior, conforme respostas obtidas em pesquisa de campo, observadas durante aplicabilidade do projeto Trilhas da Leitura, observou-se como destaque as seguintes ações efetivas do projeto: (a) promove as práticas de leitura por meio da doação de livros de forma itinerante dentro e fora do estado de Minas Gerais, o que leva a crer que o Trilhas da Leitura tem larga cobertura territorial, alcançando assim inúmeras comunidades além-fronteiras do município de Contagem; (b) promove doação de materiais danificados 


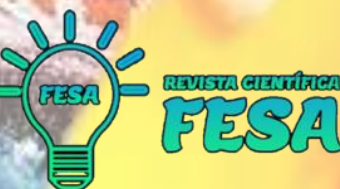

e impróprios para as práticas de leitura para associações de reciclagem de papel, denotando-se como um Projeto também de cunho socioambiental e de Responsabilidade Socioambiental; (c) promove inclusão social por meio da acessibilidade ao livro, levando a crer que o Trilhas da Leitura promove essencial ação de Educomunicação por meio da acessibilidade ao livro e de outras interfaces de leitura como o jornal, por exemplo; (d) mantêm ações coletivas que permitem o fomento de divulgação da importância da participação coletiva/interativa no processo de difusão do aporte da leitura para o desenvolvimento social, educacional, econômico, humano e dentre outros, o que leva a crer que o Trilhas da Leitura promove ações que possibilitam interação cooperativa entre entidades públicas e privadas no referente à promoção de acessibilidade ao livro para as comunidades carentes, levando, por consequência, às comunidades carentes, a democratização das práticas de leitura por meio da acessibilidade ao livro, contribuindo, assim, para a inclusão social principalmente da criança e do jovem moradores dessas comunidades desfavorecidas socioeconomicamente; (e) incentiva a Responsabilidade Socioambiental das empresas que promovem ações de arrecadação de livros e outras interfaces de leitura contribuindo para o fomento da continuidade das atividades sociais e educacionais desenvolvidas pelo projeto, levando a crer que o Trilhas da Leitura é um Projeto socioambiental e educacional autossustentável, mantendo-se com cooperação de organizações empresariais e da população em si (relevando que as pessoas participantes do Projeto também doam livros, corroborando para a continuidade das atividades do Trilhas da Leitura), salientando que uma das ações efetivas do Projeto pautase na promoção de intercâmbios de materiais de leitura (livros, revistas e jornais) entre os envolvidos no projeto.

\section{CONSIDERAÇÕES FINAIS}

Todos os aspectos citados pelos entrevistados transparecem que o projeto Trilhas da Leitura democratiza, sobretudo, o acesso à informação que, no Brasil, é elitizada e têm sofrido constantes ataques com a publicação de fakenews e inverdades científicas. Nota-se que tal iniciativa pode ser aplicada com muita facilidade nos espaços escolares, com destaque para a percepção de 
20 Jun. 2021

v. 1, n. $5,03-20$

ISSN: 2676-0428

um problema que pode, inclusive, servir de questões motivadoras para outros projetos: o alto custo da informação no Brasil.

Saber refletir para, então, criticar deve passar por etapas que envolve seleção e análise de dados, habilidades desconhecidas por muitos cidadãos brasileiros. $O$ incentivo à pesquisa motivado por questões motrizes sensíveis é uma das metas da Aprendizagem Baseada em Projetos - ABP, que vem romper com as antigas metodologias passivas que se instauraram por tanto tempo na seara educativa.

Desse modo, nota-se que a sociedade, de modo geral, e as comunidades escolares aceitam o conhecimento disponibilizado, mas carecem de iniciativas que sistematizem esse saber. Por isso, faz-se necessário perceber o projeto TriIhas da Leitura como o ponto de partida para projetos maiores e com o apoio de teorias concernentes às metodologias ativas a fim de fornecer um trabalho mais completo e com finalidades bem delimitadas.

Nota-se, portanto, que os ganhos com o projeto são imensuráveis, visto que distribui, em média, de 300 a 2000 mil livros em cada ação. Assim, as ferramentas, metaforizando os livros, são fornecidas no Trilhas da Leitura e a Aprendizagem Baseada em Projetos - ABP pode auxiliar na construção de conhecimentos concretos por meio da construção reflexiva dos saberes nos espaços escolares.

\section{REFERÊNCIAS BIBLIOGRÁFICAS}

BRASIL. Ministério da Educação Básica. Pró-Letramento. Programa de Educação Continuada de Professores dos anos iniciais do Ensino Fundamental. Editora Brasília, 2008.

CAFIERO, Delaine; MARCUSHI. Beth. Coleção Explorando o Ensino. VI. 19: 2010.

CNPQ. Iniciação Científica. 2018c. Site. Disponível em: http://memoria.cnpq.br/web/guest/iniciacao-cientifica. Acesso em: 03 nov. 2020.

CONCEIÇÃO, Midiã Silva. A Aprendizagem Baseada em Projetos na Iniciação Científica: Um Estudo no Centro Educacional Antônio Honorato em Casa Nova - BA. Monografia apresentada ao Curso de PósGraduação Lato Sensu em Educação Científica e Popularização das Ciências do Programa de PósGraduação do Instituto Federal Baiano, Campus Catu, 2021. 
FREIRE, Paulo. Pedagogia da Autonomia. Saberes necessários à prática educativa. Coleção Leitura. Paz e Terra. 21ª Edição. 2002.

GONZÁLEZ, C. G. Estrategias para trabajar la creatividad en la Educación Superior: pensamiento de diseño, aprendizaje basado en jue-gos y en proyectos. Revista de Educación a Distancia, Murcia, v. 40, jul. 2015. Disponível em: https://revistas.um.es/red/article/view/234291. Acesso em: 17 mar. 2019

QUIROZ, J. S.; CASTILLO, D. M. Una propuesta de modelo para introducir metodologías activas en educación superior. Innovación educativa, México, DF, v. 17, n. 73, p. 117-131, 2017. Disponível em: http://www.scielo.org.mx/scielo.php?script=sci_abstract\&pi-d=S166526732017000100117\&lng=es\&nrm=iso. Acesso em: 23 mar. 2019

SANTOS, W.L.P. Educação científica na perspectiva de letramento como prática social: funções, princípios e desafios. Revista Brasileira de Educação, vol.12, n.36, 2007.

SILVA, C. F. da. Lições de Casa: Estratégias Avaliativas Aplicadas pelos Docentes. Revista Científica FESA, [S. I.], v. 1, n. 2, p. 38-49, 2021. DOI: 10.29327/232022.1.2-3. Disponível em: https://revistafesa.com/index.php/fesa/article/view/11. Acesso em: 21 jun. 2021.

SOUZA, J. C. G. Integração das TDICs na Educação: Espaços Digitais. Revista Científica FESA, [S. I.], v. 1, n. 2, p. 74-88, 2021. DOI: 10.29327/232022.1.2-6. Disponível em: https://revistafesa.com/index.php/fesa/article/view/15. Acesso em: 21 jun. 2021.

SOUZA, Samir; DOURADO, Luis. Aprendizagem baseada em problemas (ABP): um método de aprendizagem inovador para o ensino educativo. Portugal: Holos, 2015. p. 182- 202. 